\title{
Development and validation of a pharmacy migraine questionnaire to assess suitability for treatment with a triptan
}

\author{
Hans-Christoph Diener · Andrew Dowson • \\ Susan Whicker · Teresa Bacon
}

Received: 20 July 2008/Accepted: 1 September 2008/Published online: 25 October 2008

(C) The Author(s) 2008. This article is published with open access at Springerlink.com

\begin{abstract}
A questionnaire (Migraine Questionnaire; MQ) was developed to help pharmacists identify consumers with migraine suitable for non-prescription treatment with a triptan. Adults, who knew or thought that they had migraine, participated in three, sequential, communitybased studies to validate the MQ. Overall, 1,353 subjects completed independent assessments with a pharmacist and a clinician (reference standard). The accuracy of the pharmacist assessment of suitability for a triptan was compared with the clinician assessment. Clinicians using their standard practice determined that triptan therapy was suitable in $76.8 \%$ of cases compared with $48.8 \%$ for pharmacists using the MQ. The lack of concordance between pharmacists and clinicians in the false-positive cases $(n=113$ of 660 subjects considered suitable for triptan by the pharmacists) usually related to headache diagnosis $(57.5 \%)$, not safety aspects. The MQ is an effective tool for pharmacists to
\end{abstract}

Electronic supplementary material The online version of this article (doi:10.1007/s10194-008-0070-6) contains supplementary material, which is available to authorized users.

\section{H.-C. Diener}

Department of Neurology, University Hospital Essen, Essen, Germany

\author{
A. Dowson \\ King's Headache Service, King's College Hospital, \\ London, UK \\ S. Whicker \\ PO Box 283, Belair, SA 5052, Australia \\ T. Bacon $(\bowtie)$ \\ GlaxoSmithKline Consumer Healthcare, St George's Avenue, \\ Weybridge KT13 0DE, UK \\ e-mail: teresa.h.bacon@gsk.com
}

guide appropriate recommendation of a non-prescription triptan for migraine.

Keywords Migraine - Sumatriptan · Naratriptan · Non-prescription medicine $\cdot$ Pharmacy questionnaire

\section{Introduction}

According to the WHO, headache should be considered as a public health concern as many people troubled by headache do not receive effective care [1]. Migraine is one of the most common types of headache and is characterised by recurrent episodes of pain with associated symptoms that frequently result in disability. A survey conducted across several countries showed that migraine affects approximately $9 \%$ of the general population [2]. Although most attacks were classified as fairly severe to very severe, many of those affected by migraine do not consult a doctor and rely on over-the-counter (OTC) medications for symptom relief [2]. The prevalence of migraine is highest among those aged between 25 and 55, the years of life when work productivity is highest [3]. Migraine poses a significant burden on individuals and on society as a result of its high prevalence and associated disability [3, 4]. Reducing the burden of migraine and closing the gap between treatment opportunities and actual practice has been recognised as a public health priority [4].

The triptans are effective and well-tolerated treatments for migraine [5]. Sumatriptan, the first triptan to be marketed, has been available as a prescription medicine for 17 years. However, relatively few people who consult a physician about migraine are prescribed a triptan (3-19\%) [2]. In an effort to broaden community access to these effective treatments, sumatriptan $50 \mathrm{mg}$ and naratriptan 
$2.5 \mathrm{mg}$ tablets were launched in 2006 for use as non-prescription medicines (available from pharmacies) in the UK and Germany, respectively. Wider access to these treatments as result of their reclassification (termed rescheduling in Australia) may result in improved treatment of migraine and reduce migraine-related disability [6], thus helping to address this public health priority [4].

To maintain the positive benefit-risk balance of a triptan with non-prescription availability, the product information was strengthened and a pharmacy questionnaire, hereafter called the Migraine Questionnaire (MQ), was developed for use by the pharmacist to guide appropriate recommendation at the point of sale.

The MQ was tested sequentially in the UK, Australia and Germany, where applications to reclassify sumatriptan (UK and Australia) or naratriptan (Germany) for non-prescription use were later submitted to the relevant regulatory agency. The design of all three studies was similar. Subjects completed two independent assessments with appointed healthcare professionals (HCPs), a pharmacist and a clinician. The aim in each study was to determine the accuracy of the pharmacist assessment of suitability for treatment with a triptan compared with the primary care clinician assessment.

The first version of the MQ was based on the proposed product information for non-prescription sumatriptan. It included a three-item migraine screening tool that had been developed and validated for use in primary care [7], and an item on headache frequency adapted from a diagnostic screening questionnaire [8]. The MQ was revised in accordance with the findings from each study. Advice from independent experts in neurology, cardiology, general practice and pharmacy practice and results from a user testing study with consumers and pharmacists were also taken into account in developing the MQ.

\section{Methods}

\section{Study design}

All three studies were multi-centred and community-based. Adults $\geq 18$ years were recruited through advertisements (print and radio) local to the study sites. Individuals who wanted to participate in the studies contacted a call centre, and appointments were arranged. Each subject completed two assessments with appointed independent HCPs. No treatment was provided in any of these studies.

All pharmacists were trained prior to taking part in the studies. The pharmacists were provided with information and a training manual on migraine and its treatment and on the use of the MQ. The MQ contained guidance notes to assist the pharmacist during the assessments (see
Appendix). Minor differences between the product information for sumatriptan and naratriptan were reflected in the text of the MQ tested in Germany (naratriptan). Training for the clinicians was less intensive. A copy of the prescribing information (product information in Australia) for the prescription product was provided.

The first assessment took place in a community pharmacy. The pharmacist used the MQ to assess whether the subject had migraine and was potentially suitable for nonprescription treatment with sumatriptan (UK and Australia) or naratriptan (Germany). The pharmacist was not required to make a formal diagnosis of migraine although a subject was considered to have migraine if certain responses were provided to those items in the MQ that concerned migraine history.

The second assessment occurred within 2 weeks. The subject was assessed for migraine and suitability for sumatriptan (or naratriptan) by a primary care clinician using his or her standard clinical practice. The clinician's assessment was the reference standard. The clinicians had no prior clinical knowledge about the subjects other than that they were aged $\geq 18$ years and knew or thought they suffered from migraine.

Each study was conducted in accordance with the principles of the Declaration of Helsinki (1996). Ethics approval was obtained from: RSSL Independent Ethics Committee, Reading (UK); the National Research and Evaluation Ethics Committee of the Royal Australian College of General Practitioners (Australia), and the Ethics Commissions for the (1) University of Duisburg-Essen, (2) North Rhine and (3) Westfalen-Lippe. All subjects provided written, informed consent.

\section{Statistics}

A pilot study was conducted in the UK with a shortened version of the MQ. The results from this study (not shown) were used in the sample size calculation for the three validation studies described herein.

The primary endpoint was the false-positive rate, one of the measures of the accuracy of the pharmacist assessment of subject suitability. A false-positive was defined as a subject considered suitable for sumatriptan or naratriptan by the pharmacist, but not by the clinician. The falsepositive rate is the total number of false-positives expressed as a proportion of the total number of subjects considered suitable by the pharmacists. Other measures of accuracy included specificity, positive predictive value, sensitivity, and negative predictive value. The proportions of interest were estimated with $95 \%$ confidence intervals (CIs). For calculation of the $95 \%$ CIs, either the normal approximation or the exact method was used as appropriate. No hypotheses were tested. 


\section{Results}

Study population

It was planned to recruit 450 subjects for the UK study; the recruitment target was 465 in the other two studies. Actual numbers of subjects recruited and those who completed both assessments are shown in Table 1 together with the number of participating HCPs. The number of clinicians was increased in the Australian and German studies to reduce the number of assessments per clinician.

\section{Demographics}

Across the three studies, most subjects who completed both assessments were female (79-83\%) and Caucasian (9199\%), and the mean age ranged from 36 to 42 years.

Migraine diagnosis by the clinicians

The proportion of subjects diagnosed with migraine by the clinicians was similar across the studies ranging from 84.2 to $88.9 \%$. However, the diagnosis rate varied between the individual clinicians. For the five clinicians in the UK study, this ranged from 68.5 to $100 \%$, each of whom assessed between 55 and 110 subjects. There were also marked differences between clinicians in the distribution of the specific headache diagnoses: of 31 subjects diagnosed with chronic daily headache in the UK study, one clinician identified $87 \%$ of these cases, and of 20 subjects diagnosed with tension-type headache, one other clinician identified $50 \%$ of these cases.

Assessment of suitability for treatment with a triptan

A summary of the accuracy of the pharmacist assessment of suitability for a triptan based on subjects who completed both assessments is shown in Table 2. In all three studies, pharmacists were more cautious than clinicians in assessing suitability. The overall proportion of subjects determined to be suitable for a non-prescription triptan (660/1,353;

Table 1 Numbers of subjects and HCPs participating in the MQ studies

\begin{tabular}{lrcc}
\hline & \multicolumn{3}{c}{ Study location } \\
\cline { 2 - 4 } & UK & Australia & Germany \\
\hline Pharmacists & 25 & 18 & 27 \\
Clinicians & 5 & 11 & 11 \\
Total number of subjects recruited & 462 & 471 & 470 \\
$\begin{array}{l}\text { Subjects who completed assessments } \\
\quad \text { with both HCPs }\end{array}$ & 439 & 456 & 458 \\
\hline
\end{tabular}

Table 2 Assessment of subject suitability for triptan treatment by HCPs

\begin{tabular}{|c|c|c|c|c|c|c|c|c|c|}
\hline & UK s & tudy $^{\mathrm{a}}$ & & Aust & lian & & $\begin{array}{l}\text { Gern } \\
\text { Clini }\end{array}$ & an st & \\
\hline & $\begin{array}{l}\text { Suita } \\
\text { suma }\end{array}$ & $\begin{array}{l}\text { ble fo } \\
\text { tripta }\end{array}$ & & $\begin{array}{l}\text { Suita } \\
\text { suma }\end{array}$ & $\begin{array}{l}\text { le for } \\
\text { iptan }\end{array}$ & & $\begin{array}{l}\text { Suita } \\
\text { narat }\end{array}$ & $\begin{array}{l}\text { le fo } \\
\text { iptan }\end{array}$ & \\
\hline & Yes & No & Total & Yes & No & Total & Yes & No & Total \\
\hline Pharm & lacist & & & & & & & & \\
\hline Yes & 156 & 39 & 195 & 130 & 26 & 156 & 261 & 48 & 309 \\
\hline No & 161 & 83 & 244 & 221 & 79 & 300 & 110 & 39 & 149 \\
\hline Total & 317 & 122 & 439 & 351 & 105 & 456 & 371 & 87 & 458 \\
\hline
\end{tabular}

a Sumatriptan $50 \mathrm{mg}$ for the studies in the UK and Australia; naratriptan $2.5 \mathrm{mg}$ in Germany

$48.8 \%)$ was lower than that for a prescription triptan $(1,039 /$ $1,353 ; 76.8 \%)$.

Accuracy of the pharmacist assessment of suitability

Individual measures of the accuracy of the pharmacist assessment of suitability are shown in Table 3 . The falsepositive rate was $17.1 \%(113 / 660)$ overall, and $20,16.7$ and $15.5 \%$ in the UK, Australian and German studies, respectively.

Sensitivity and specificity were relatively low (Table 3 ). This is not surprising given that the pharmacists and the clinicians were assessing suitability in accordance with the labelling for non-prescription and prescription triptans, respectively.

The false-positive cases $(n=113)$ are of interest as these could flag potential safety concerns regarding the pharmacist recommendation. Accordingly, the reason(s) as to why the clinicians classified these subjects as unsuitable for a triptan were reviewed. The reasons were categorised into two groups as shown below.

\section{False-positive cases: subjects who did not have migraine}

Overall, $57.5 \%$ of false-positive subjects (65/113) had been diagnosed with a headache other than migraine by the clinicians (Table 4). Chronic daily headache was the most common diagnosis $(54.5 \%)$, reflecting the high prevalence of this diagnosis in the UK study. Tension-type headache was the most frequent diagnosis for false-positives made by clinicians in the Australian (64.7\%) and German (84.6\%) studies.

Out of the 65 false-positive subjects with a diagnosis other than migraine, $56.9 \%$ (range $41.2-72.3 \%$ across the studies), had previously been diagnosed with migraine and/ or prescribed medication to treat migraine by their doctor, and $89.2 \%$ (range $77.3-94.1 \%$ ) gave a positive response to 
Table 3 Analysis of the pharmacist assessment of suitability

\begin{tabular}{|c|c|c|c|c|c|c|}
\hline \multirow[t]{2}{*}{ Measure } & \multicolumn{2}{|c|}{ UK study $^{\mathrm{a}}(n=439)$} & \multicolumn{2}{|c|}{ Australian study $^{\mathrm{a}}(n=456)$} & \multicolumn{2}{|c|}{ German study $^{\mathrm{a}}(n=458)$} \\
\hline & Value & $95 \% \mathrm{CI}$ & Value & $95 \% \mathrm{CI}$ & Value & $95 \% \mathrm{CI}$ \\
\hline False-positive rate & $39 / 195=0.200$ & $0.144,0.256$ & $26 / 156=0.167$ & $0.108,0.225$ & $48 / 309=0.155$ & $0.115,0.196$ \\
\hline Specificity & $83 / 122=0.680$ & $0.598,0.763$ & $79 / 105=0.752$ & $0.670,0.835$ & $39 / 87=0.448$ & $0.344,0.553$ \\
\hline Positive predictive value & $156 / 195=0.800$ & $0.744,0.856$ & $130 / 156=0.833$ & $0.775,0.892$ & $261 / 309=0.845$ & $0.804,0.885$ \\
\hline Sensitivity & $156 / 317=0.492$ & $0.437,0.547$ & $130 / 351=0.370$ & $0.320,0.421$ & $261 / 371=0.704$ & $0.657,0.750$ \\
\hline Negative predictive value & $83 / 244=0.340$ & $0.281,0.400$ & $79 / 300=0.263$ & $0.213,0.313$ & $39 / 149=0.262$ & $0.191,0.332$ \\
\hline
\end{tabular}

${ }^{\text {a }}$ Sumatriptan $50 \mathrm{mg}$ for the studies in the UK and Australia; naratriptan $2.5 \mathrm{mg}$ in Germany

Table 4 Clinician-reported headache diagnosis in false-positive subjects who did not have migraine

\begin{tabular}{llll}
\hline Headache diagnosis & \multicolumn{3}{l}{ False-positive subjects } \\
\cline { 2 - 4 } & $\begin{array}{l}\mathrm{UK} \\
(n=39)\end{array}$ & $\begin{array}{l}\text { Australia } \\
(n=26)\end{array}$ & $\begin{array}{l}\text { Germany }^{\mathrm{a}} \\
(n=48)\end{array}$ \\
\hline $\begin{array}{l}\text { Chronic daily/chronic } \\
\text { headache }\end{array}$ & 12 & 3 & 1 \\
$\begin{array}{l}\text { Tension-type headache } \\
\text { Cluster headache }\end{array}$ & 7 & 11 & 22 \\
Cervicogenic headache & - & - & - \\
Other & $1^{\mathrm{b}}$ & - & 3 \\
Missing & 1 & $3^{\mathrm{c}}$ & $1^{\mathrm{d}}$ \\
Total & 22 & - & - \\
\hline
\end{tabular}

a Two diagnoses of non-migraine headache were given to one subject

b "Multiple headaches and probably did have migraine in the past. Now many headaches not migraine"

${ }^{c}$ Headaches associated with hypoglycaemia $(n=1)$; no headache $(n=1)$; no symptoms of migraine $(n=1)$

d Atypical facial neuralgia

at least two out of the three items in the migraine screening tool [7] that formed part of the MQ.

False-positive cases: subjects with migraine but whose general medical history was incompatible with triptan treatment

Overall, $42.5 \%$ of the false-positive subjects (48/113) were diagnosed with migraine by the clinicians but deemed unsuitable for a triptan for other reasons (Table 5). In some cases, the pharmacist appeared to have missed contraindications for non-prescription supply of triptan, e.g. hypertension $(n=2)$, previous bad reaction/allergy to triptan $(n=3)$ and rare variant migraine $(n=2$; both cases were identified by the same clinician). Several other reasons provided were considered clinically unimportant, e.g. migraine managed well with current over-the-counter (OTC) treatments.
Table 5 Clinician-reported reasons why false-positive subjects with migraine were unsuitable for a triptan

\begin{tabular}{|c|c|c|c|}
\hline \multirow{2}{*}{$\begin{array}{l}\text { Clinician reason why subject } \\
\text { was unsuitable for triptan }{ }^{\mathrm{a}}\end{array}$} & \multicolumn{3}{|c|}{ False-positive subjects } \\
\hline & $\begin{array}{l}\mathrm{UK}^{\mathrm{b}} \\
(n=39)\end{array}$ & $\begin{array}{l}\text { Australia }^{\mathrm{b}} \\
(n=26)\end{array}$ & $\begin{array}{l}\text { Germany }^{\mathrm{b}} \\
(n=48)\end{array}$ \\
\hline $\begin{array}{l}\text { Vomits early in migraine } \\
\text { attack/needs non-tablet } \\
\text { medication due to vomiting } \\
\text { or requiring very swift } \\
\text { onset of action }\end{array}$ & 4 & 1 & 3 \\
\hline Duration of headache too short & 3 & - & - \\
\hline $\begin{array}{l}\text { Migraine managed well with } \\
\text { current OTC treatments }\end{array}$ & 3 & - & $11^{\mathrm{c}}$ \\
\hline Aura only & 2 & - & \\
\hline Did not respond to triptans & 1 & 2 & 5 \\
\hline $\begin{array}{l}\text { Taking selective serotonin } \\
\text { reuptake inhibitor }\end{array}$ & 2 & - & - \\
\hline $\begin{array}{l}\text { Contraindicated medical } \\
\text { condition }\end{array}$ & - & $2^{\mathrm{d}}$ & - \\
\hline $\begin{array}{l}\text { Migraine not suitable for } \\
\text { sumatriptan/naratriptan }\end{array}$ & - & $2^{\mathrm{e}}$ & $2^{\mathrm{f}}$ \\
\hline $\begin{array}{l}\text { Previous bad reaction or allergy } \\
\text { to sumatriptan/naratriptan }\end{array}$ & 1 & 1 & 1 \\
\hline Other & $1^{\mathrm{g}}$ & $1^{\mathrm{h}}$ & - \\
\hline Total & 17 & 9 & 22 \\
\hline
\end{tabular}

${ }^{a}$ Where a clinician identified multiple reasons for unsuitability, the first medically significant reason is listed

b Sumatriptan $50 \mathrm{mg}$ for the studies in the UK and Australia; naratriptan $2.5 \mathrm{mg}$ in Germany

c All 11 cases identified by one clinician

${ }^{\mathrm{d}}$ Uncontrolled hypertension $(n=2)$

e Hemiplegic migraine $(n=2)$; both cases identified by one clinician

${ }^{\mathrm{f}}$ Clinician reported- "Post-traumatic stress disorder, coordination barely possible, memory impaired, alternative therapies" in one case. No further information from the clinician for the second case

g Female, 27.5 years, with cardiac pacemaker. No personal or family history of heart disease according to MQ responses collected by pharmacist

h Taking antipsychotic medication $(n=1)$ 
Table 6 Pharmacist and clinician assessment of triptan suitability in subjects recognised by the pharmacist to have contraindications related to cardiovascular disease, or cardiac risk factors

\begin{tabular}{llll}
\hline & \multicolumn{3}{l}{$\begin{array}{l}\text { Suitability assessments by the } \\
\text { pharmacists and clinicians }\end{array}$} \\
\cline { 2 - 3 } $\mathrm{UK}^{\mathrm{a}}$ & Australia $^{\mathrm{a}}$ & Germany $^{\mathrm{a}}$ \\
$(n=439)$ & $(n=456)$ & $(n=458)$ \\
\hline
\end{tabular}

Subjects with at least one contraindication related to cardiovascular disease ${ }^{\mathrm{b}}$

$\begin{array}{llll}\text { No. of subjects } & 37 & 16 & 47 \\ \text { Pharmacist-assessed suitability } & 5.4 \% & 0 \% & 25.5 \% \\ & 2 / 37 & 0 / 16 & 12 / 47 \\ \text { Clinician-assessed suitability } & 62.2 \% & 68.8 \% & 72.3 \% \\ & 23 / 37 & 11 / 16 & 34 / 47\end{array}$

Subjects with at least three cardiac risk factors ${ }^{\mathrm{c}}$

$\begin{array}{llll}\text { No. of subjects } & 16 & 11 & 32 \\ \text { Pharmacist-assessed suitability } & 0 \% & 0 \% & 9.4 \% \\ & 0 / 16 & 0 / 11 & 3 / 32 \\ \text { Clinician-assessed suitability } & 56.3 \% & 63.6 \% & 81.3 \% \\ & 9 / 16 & 7 / 11 & 26 / 32\end{array}$

a Sumatriptan $50 \mathrm{mg}$ for the studies in the UK and Australia; naratriptan $2.5 \mathrm{mg}$ in Germany

b History of heart disease, stroke or transient ischaemic attack, peripheral vascular disease/problems with circulation

c As listed in the product information for non-prescription triptans: women who are post-menopausal; men aged over 40; high cholesterol; parent, brother or sister developed heart disease before the age of 60; regularly smoke more than 10 cigarettes per day; diabetic; clearly obese

Contraindications related to cardiovascular disease and cardiac risk factors

Use of a triptan in individuals with a history of, or at high risk of, cardiovascular disease is an important safety consideration. The pharmacists identified 100 subjects with one or more contraindications relating to cardiovascular disease (Table 6). These contraindications apply to sumatriptan and to naratriptan, irrespective of prescription or non-prescription status. Most of these subjects $(86.0 \%)$ were classed as unsuitable for treatment with a triptan by the pharmacist. The clinicians may have placed less weight on this aspect of medical history in assessing the overall benefit-risk for individual subjects as only $32.0 \%$ of these subjects were reported to be unsuitable for treatment with a triptan.

The MQ reflects the requirements of the product information for non-prescription sumatriptan and naratripan as subjects with three or more cardiac risk factors (see Table 6 footnote) are considered unsuitable for a triptan. Labelling for the prescription products is less rigid and enables clinicians to use clinical judgement in assessing this aspect. In almost all cases, the pharmacists concluded that subjects with three or more risk factors were not suitable for a non-prescription triptan (Table 6). Overall, $94.9 \%$ of subjects with at least three risk factors were considered to be unsuitable for a triptan by the pharmacists, whereas the clinicians reported that only $28.8 \%$ of these subjects were unsuitable for a triptan.

Suitability rates for pharmacy supply of a triptan

The lowest pharmacist suitability rate was found in the Australian study (34.2\%; Table 2). Two questions were identified as being more restrictive than had been intended. The pharmacists were provided with guidance notes to aid interpretation of responses to the MQ (see Appendix). The guidance notes for the MQ in the Australian study stated that those subjects whose migraine headaches lasted $>24 \mathrm{~h}$ or who had four or more migraine headaches per month should be referred to their doctor (see Appendix; MQ for Australian Study, Question 5). Overall, 35.8\% of subjects in the Australian study reported a duration of $>24 \mathrm{~h}$ and $22.0 \%$ reported at least four migraines per month headaches; 20.9 and $9.0 \%$, respectively, thus were considered unsuitable a non-prescription sumatriptan for these reasons alone.

In the subsequent study in Germany, the guidance was relaxed to allow the pharmacist to recommend a triptan for subjects whose migraine headaches lasted $>24 \mathrm{~h}$ or who reported four or more attacks per month, while still advising referral to a doctor. The pharmacist suitability rate increased to $67.5 \%$ (Table 2).

\section{Discussion}

Three studies were conducted in the UK, Australia and Germany to validate the MQ. The study populations reflected the typical demographic profile of migraine sufferers being predominantly female and aged 30-40 [2, 9]. Pharmacists were less likely to conclude that a subject was suitable for a triptan $(48.8 \%)$ than clinicians in these studies $(76.8 \%)$. The sensitivity of the pharmacist assessment of suitability was low, as expected, given that the MQ reflects the conservative wording of the non-prescription product information. Contraindications, warnings and precautions in the product labelling are typically strengthened when a medicine is reclassified for non-prescription use.

Changes to the text of the MQ in the three studies may explain why the pharmacist suitability rates ranged from 34.2 to $67.5 \%$, while suitability rates, as determined by the clinicians, were generally consistent (72.2-81.0\%).

The false-positive rate declined progressively from 20.0 to $15.5 \%$ across the studies over time. Discordance between the pharmacists and clinicians was primarily related to headache diagnosis. The clinicians gave a diagnosis other than migraine in over half of these cases, with 
tension-type headache being the most common. Triptans are specific for migraine; therefore, no therapeutic benefit would be expected in tension-type headache [10]. Potential risks associated with triptan use in this population are likely to be low as the pharmacist assessment also considers general medical history. There were no significant safety concerns with most of the remaining false-positive subjects, e.g. migraine being managed well with current OTC treatments $(n=14)$, vomiting during the migraine attack $(n=8)$. Potential safety concerns were raised in a few cases where a clinician reported a previous adverse reaction to sumatriptan or naratriptan $(n=3)$, hypertension $(n=2)$, and hemiplegic migraine $(n=2)$ : these histories had not been reported by the pharmacists. Hypertension, hemiplegic migraine and hypersensitivity to sumatriptan/ naratriptan, are contraindicated for the non-prescription products. Two subjects were classified as unsuitable for a triptan by the clinicians because they were taking selective serotonin reuptake inhibitors (SSRIs). Concomitant use of SSRIs is included as a warning, not a contraindication, on the product information for prescription and non-prescription triptans. Co-prescription of triptans and SSRIs is widespread but cases of serotonin syndrome are rare [11], and it is unclear whether concomitant use increases the risk of serotonin syndrome [12]. Despite the falsepositive cases, the MQ is considered to be of value in guiding appropriate recommendation by pharmacists.

The Triptan Cardiovascular Safety Expert Panel concluded that the safety profile of triptans is well defined and appears to reflect a very low risk of serious cardiovascular adverse events based on use in patients without known or suspected coronary artery disease [13]. The pharmacists, using the $\mathrm{MQ}$, were more cautious than the clinicians in evaluation of cardiovascular contraindications and cardiac risk assessment (Table 6).

Post-marketing safety data are considered to provide a reflection of overall prescribing behaviour. Since pharmacists were more conservative in recommending a triptan than clinicians in these studies, non-prescription supply would not be expected to reduce the benefit-risk balance, assuming that the clinicians are representative of the general population of prescribers. The UK and German regulatory authorities reviewed all relevant safety data and concluded that sumatriptan $50 \mathrm{mg}$ and naratriptan $2.5 \mathrm{mg}$, respectively, are suitable for non-prescription use. GSK undertakes a regular, systematic review of the safety data. There has been no change in the pattern of adverse event reporting for either sumatriptan or naratriptan since they were launched as non-prescription medicines.

The intention in our studies was for clinicians to use their standard practice to assess patients with migraine because this represents the benchmark against which the pharmacists should be compared. Accordingly, the clinicians were not provided with tools to assist in the recognition of migraine. Not surprisingly, the clinicians did not have a consistent approach to the diagnosis of migraine. While 'gold standard' diagnostic criteria have been developed [14], directing their use would have been inappropriate in these studies.

Questions relating to migraine headache duration and frequency in the version of the MQ tested in Australia were unduly restrictive. The MQ guidance notes were therefore reviewed and relaxed for the final study to allow pharmacists to consider a subject as potentially suitable for a triptan if duration was $>24 \mathrm{~h}$ or if migraine occurred at least four times per month. There is no clinical reason to rule out supply of a non-prescription triptan in either situation, although referral to a doctor is appropriate because prolonged or frequent migraine attacks may be indicators for prophylactic therapy and/or further investigation. In a survey of adult migraine sufferers, the median duration of the headache phase of an untreated migraine attack was $24 \mathrm{~h}$, with a mean duration of $28 \mathrm{~h}$ (males) and $37 \mathrm{~h}$ (females), and $13 \%$ reported an attack frequency of greater than four per month [9]. The pharmacist suitability rate increased from $34.2 \%$ in the Australian study to $67.5 \%$ in the German study. The MQs that are being used in the UK ${ }^{1}$ and in Germany to support pharmacist recommendation of a triptan are similar in content and structure to the version tested in the German study.

A reduction in migraine-related disability is considered to be one of the key benefits of making triptans available from pharmacies [6]. The importance of consumers receiving professional advice at the point of sale has also been recognised [6]. Use of the MQ addresses this need by guiding a dialogue between the pharmacist and consumer. The MQ has been shown to be an effective tool to support pharmacist recommendation of a non-prescription triptan.

Acknowledgments The authors thank the following colleagues from GlaxoSmithKline: Alison Hughes and Howard Marsh for assistance with these studies, and Mairead North and Darren Targett for advice and statistical analysis. The authors also thank the clinicians and pharmacists who participated in these studies.

Conflict of interest statement Prof. Dr. H.-C. Diener has received honoraria from Addex Pharma, Allergan, Almirall, AstraZeneca, Bayer Vital, Berlin Chemie, CoLucid, Böhringer Ingelheim, BristolMyers Squibb, GlaxoSmithKline, Grünenthal, Janssen-Cilag, Lilly, Hoffman-La Roche, 3M Medica, MSD, Novartis, Johnson \& Johnson, Pierre Fabre, Pfizer, Schaper and Brümmer, SanofiAventis, Weber \& Weber.

Dr. A. Dowson has received honoraria from Allergan, Almirall/ Organon, AstraZeneca, GlaxoSmithKline, Janssen-Cilag, MSD, Novartis, Pfizer and Vernalis/Menarini.

Dr. S. Whicker has received honoraria from GlaxoSmithKline and Sanofi.

\footnotetext{
${ }_{1}$ Additional changes were made to the MQ at the request of the UK regulatory authority.
} 
Open Access This article is distributed under the terms of the Creative Commons Attribution Noncommercial License which permits any noncommercial use, distribution, and reproduction in any medium, provided the original author(s) and source are credited.

\section{References}

1. World Health Organization (2004) Headache disorders. Fact Sheet No. 277, March 2004. Accessed 29 June 2008

2. MacGregor EA, Brandes J, Eikermann A (2003) Migraine prevalence and treatment patterns: the global Migraine and Zolmitriptan Evaluation survey. Headache 43:19-26

3. Lipton RB, Stewart WF, Scher AI (2001) Epidemiology and economic impact of migraine. Curr Med Res Opin 17(suppl 1): $\mathrm{s} 4-\mathrm{s} 12$

4. American Association for the Study of Headache, International Headache Society (1998) Consensus statement on improving migraine management. Headache 38:736

5. Ferrari MD, Roon KI, Lipton RB, Goadsby PJ (2001) Oral triptans (serotonin 5-HT(1B/1D) agonists) in acute migraine treatment: a meta-analysis of 53 trials. Lancet; 358:1668-1675

6. Tfelt-Hansen P, Steiner TJ (2007) Over-the-counter triptans for migraine: what are the implications? CNS Drugs 21:877-883

7. Lipton RB, Dodick D, Sadovsky R, Kolodner K, Endicott J, Hettiarachchi J, Harrison W (2003) A self-administered screener for migraine in primary care: the ID Migraine ${ }^{(\mathrm{TM})}$ validation study. Neurology 61:375-382
8. Dowson AJ, Turner A, Kilminster S, Glover C, Lipscombe S (2005) Development and validation of the Headache Diagnostic Screening Questionnaire (DSQ): a new questionnaire for the differential diagnosis of headache for use in primary care. Headache Care 2:111-118

9. Steiner TJ, Scher AI, Stewart WF, Kolodner K, Liberman J, Lipton RB (2003) The prevalence and disability burden of adult migraine in England and their relationships to age, gender and ethnicity. Cephalalgia 23:519-527

10. Diener HC, Kaube H, Limmroth V (1998) A practical guide to the management and prevention of migraine. Drugs 58:811-824

11. Tepper S, Allen C, Sanders D, Greene A, Boccuzzi S (2003) Coprescription of triptans with potentially interacting medications: a cohort study involving 240268 patients. Headache 43:4448

12. Shapiro RE, Tepper SJ (2007) The serotonin syndrome, triptans, and the potential for drug-drug interactions. Headache 47:266269

13. Dodick D, Lipton RB, Martin V, Papademetriou V, Rosamond W, MaassenVanDenBrink A, Loutfi H, Welch KM, Goadsby PJ, Hahn S, Hutchinson S, Matchar D, Silberstein S, Smith TR, Purdy RA, Saiers J (2004) Consensus statement: cardiovascular safety profile of triptans (5-HT agonists) in the acute treatment of migraine. Headache 44:414-425

14. Headache Classification Subcommittee of International Headache Society (2004) The international classification of headache disorders, 2nd edn. Cephalalgia 24(Suppl 1):1-160 